\title{
MJMR ASSESSMENT OF PHYSICAL HEALTH PROBLEMS ALONG WITH RISK FACTORS AND PSYCHOLOGICAL HEALTH PROBLEMS OF THE VICTIMS ATTENDING POST- DISASTER MEDICAL CARE FACILITY AT UTTARAKHAND, INDIA
}

\author{
Anita Paul Samanta ${ }^{1 *}$, Ansuman Mitra ${ }^{2}$ \\ IPsychiatric Nursing W.B.U.H.S, West Bengal, India \\ ${ }^{2}$ In-charge, MSC Disaster Response Cell,Medical Service Centre (MSC); Deputy Medical \\ Superintendent, Calcutta Heart Clinic \& Hospital, West Bengal, India \\ *Correspondence Author’s Email: anitasamantap1973@gmail.com
}

\begin{abstract}
A retrospective medical record analysis was done to identify the physical problems, related risk factors, and psychological problems faced by flood affected victims of Uttarakhand. The main aim of the study is to disintegrate the information related to the impact of the disasters on people and sustainable environment, which can be prevented with appropriate preparedness and measures. A total of 2311 patients were taken care. Of these, $(41.8 \%$ ) were middle-aged ( $18-50$ years), $35 \%$ were below 18 years, and $23.2 \%$ of them were above 50 years of age. $26.76 \%$ of them suffering from RTI, $25.33 \%$ from GI problems, $10.84 \%$ had dental problems, and $10.41 \%$ skin problems. $7.41 \%$ of the victims had orthopedic problems, $5.75 \%$ ENT issues, $5.48 \%$ eye infections, $4.68 \%$ CVS problems. Again this is to be noted that $3.34 \%$ of them were suffering from UTI. Data also depicted that $39.88 \%$ of the people was suffering from acute stress disorder. Identified risk factors were unavailability of safe drinking water, food, gathering of the victims in a small or uncovered space, severe financial losses and loss of the near and dear one respectively. The victims received health care and treatment for a period of one year. People suffering from severe illness were transferred to the tertiary care hospital. The caregivers also suffered from diarrhea and fever occasionally.
\end{abstract}

Keywords: Physical Health Problems, Psychological Health Problems, Risk Factors, Victims and Post Disaster Medical Care Facility

\section{INTRODUCTION}

The catastrophes are mostly local. The effects of the event will be inherited by populations, regardless of whether it is the smallest storm, the biggest hurricane, an act of terrorism, or a technical accident. Emergency response requires a number of steps to protect life and property and to deal with the social damage caused by disasters. Disasters undermine development that is sustainable. They lead to loss of life and trigger injuries, with life-changing consequences often. In addition, homes, schools, health centres, hospitals, services, highways, markets and other social and economic infrastructure are destroyed and the natural environment is impaired (Benson, 2016). These direct, physical losses have further indirect consequences, disrupting livelihoods.

Emergent groups perform many different types of activities in disasters. Both the physical and psychological health are jeopardized. Gastro-intestinal problems, respiratory problems, skin problems, musculoskeletal problems, eye problems, cardiovascular problems are the most commonly occurring problems. Psychological trauma is not addressed most of the time. While these aspects have great impact on the outcome of the physical health of the victims after disaster, provision of health care with the arrangement of relief camp can bridge the gap between sustainable environment and recovery.

\section{Objectives}

1. To assess the physical problems faced by the disaster victims

2. To find out the risk factors affecting early recovery of the victims 
3. To identify psychological problems faced by the victims.

\section{Background}

Amongst all the natural disasters, floods are most common. Though theyaffect most countries around the world, poor sections of the population are particularly vulnerable to flood risk. Fewer may be able to afford medical care in the aftermath of a disaster, resulting in long-term impacts on health.A catastrophic flood struck the Kedarghati and surrounding valleys of Uttarakhand in 2013. It is evident that the villagers have rescued travellers, fed them, gave them there own food and water after the disaster. Hundreds of bridges have been washed away. Hence the travellers had to be airlifted to be brought back. The presence of thousands of unaccounted tourists confuse the focus of the response system. 'Rescue' had to be undertaken due to the pressure of thousands upon thousands of tourists and pilgrims from all over the country and abroad, lying stranded with diminishing hope of being found, food or drinking water once the meagre rations at the disposal of the villagers who guided, rescued and sheltered thousands had begun to run dry.

About 4,000 people were killed by the flash floods, causing unparalleled damage to highways, habitats, tourism and business sectors, hydroelectric projects, agriculture, etc. Over 1,00,000 pilgrims were in the area during the tragedy, in addition to around 3 million local people. Unofficial allegations have caused more than 10,000 deaths, damage to nearly 8,000 kilometres of motor roads, and serious damage to 200 bridges. At least 30 under construction or completed hydropower projects have been either completely destroyed or seriously damaged. Around 30 government buildings have also been completely or partially destroyed, including para-military camps, guesthouses, food outlets, government offices and schools. An initial evaluation made by us indicates that more than 5,000 hill villages and 30 hill urban clusters have been seriously impacted. Though the temple survived, the famous Kedarnath shrine was completely destroyed. [Dr. S P Sati].

Health is grossly neglected. Health centres are very few in number, and shut down. After a long drive or trek, one can find a centre with a pharmacist, who is thus practising and accepted as doctor

Disaster mental health is a burgeoning field with various possibilities for professional engagement in efforts to plan, respond, and recover. The health and well-being effects of disasters are various. Deaths tend to happen from blunt trauma in most disasters; for example, when houses, including hospitals, collapse (Davis, Sacoby, Martin, Glover \& Syendsen, 2010).

This study performed a detailed medical analysis of physical problems with probable risk factors and psychological problems based on comprehensive medical data of the affected people for two months in the immediate post-disaster phase to share the experiences and lessons learned from emergency medical aid operations in the hills.

There are 2 main types of disasters: natural and technological. Natural disasters occur outside the control of humans, whereas technological disasters are breakdowns in human-made systems (Davis, Sacoby, Martin, Glover \& Syendsen, 2010). Immediate threats to public health during the response to a disaster are quite evident.

Disasters pose greater threats to communities lacking resources and access to health care, which are precursors to health care disparities.

Sustainable healthcare systems are done without exhausting natural resources or causing ecological harm by ensuring high quality care and enhancing public health. The first problem must be the consequences of resource availability in order to achieve a resilient and sustainable post-disaster safe climate. Sustainability will help to minimise global catastrophe mortality by 2030 , with the goal of reducing the average global mortality rate per 100,000 between 2020-2030 relative to 2005-2015; dramatically reducing the number of people impacted worldwide by 2030 (Benson, 2016).

Health and health care disparities are seldom addressed in disaster response and recovery planning. Disaster epidemiology has been recognized as an emerging field with the expansion of human populations into disastersusceptible regions and global climate change looming on the horizon.

Professional Health Care Providers are the trained and registered personnel namely Doctors, Nurses, Psychologists and Laboratory technicians.

Others who participated in the post-disaster medical response include auxiliary, para medical workers, 
engineers, university, college and schools teachers and students. To help the community as medical aid is irregular and far inaccessible, involvement of local students and youth to get hands-on experience as health aid in the base \& mobile camps, and first aid training to improve the level health intervention in their villages was highly effective.

\section{LITERATURE REVIEW}

(Makwana, 2019) conducted a narrative review to understand the linkage between disaster and its impact on mental health and findings revealed that emotional instability, anxiety, trauma and other psychological symptoms are common after disaster and play a major role in individual and communities resilience process. They recommended that psycho-education and its application plays a crucial role in adaptation with negative situation (Makwana, 2019).

(Seto, et al. 2011-12) conducted a study on mental health and psychosocial support. This study aimed to reveal (1) the types of activities that were actually provided as mental health and psychosocial support (MHPSS) in the long-term phase after the Great East Japan Earthquake (GEJE) and (2) the problems that must be addressed to provide post-disaster MHPSS activities. Regarding the support provided in community spaces, free MHPSS, such as "monthly psychosocial case work" or "bimonthly maternal and child health consultations provided by clinical psychologists", were offered.

(Tsubokura, et al. 2011) conducted a study to find out the metabolic problems of the disaster affected victim of Japan. The study findings showed that significantly higher values of body weight, body mass index, waist circumference, and HbA1C and lower high-density lipoprotein cholesterol levels were found at the postquake screening when compared with the pre-quake levels $(p=0.004, p=0.03, p=0.008, p<0.001$, and $\mathrm{p}=$ 0.03 , respectively). A significantly higher proportion of subjects in the tsunami group with high $\mathrm{HbA1C}$, defined as $\geq 5.7 \%$, was observed after the quake $(34.3 \%)$ than before the quake $(14.8 \%)(p<0.001) .5$

(Yzermans et al. 2005) Using the electronic medical records of general practitioners, a longitudinal analysis of $(89$ percent of all) casualties $(\mathrm{n}=9329)$ and controls $(\mathrm{n}=7392)$ with pre-disaster baseline morbidity for 16 months and post-disaster data for 2.5 years was carried out. Symptoms and diagnoses were identified using the International Primary Care Classification (ICPC). Prevalence rates for symptom clusters were contrasted between pre - and post-disaster victim and control groups. In hierarchical linear models, risk factors for developing health problems were examined. The study results found that two and a half years after the disaster, the incidence of psychological issues in victims who had to relocate was around twice as high and one-third higher than controls in non-relocated victims. Victims with psychological problems pre-disaster were at a higher risk for psychological problems post-disaster. In particular, in a time of heightened media coverage, relocated victims displayed an abundance of medically unexplained physical symptoms (MUPS). Compared to their pre-disaster levels and compared with the control group, both groups of victims showed some rise in gastrointestinal (GI) morbidity 2.5 years after the disaster.6

\section{METHODOLOGY}

Management of flood affected victims was provided by professional health care providers from 11(eleven) states of India under the guidance of Medical Service Centre at flood relief medical relief camps in the disaster affected areas of Uttarakh and Flood in the year 2013. Hand written documents were kept by the health care providers. To fulfill the study objectives more than 100 documents were reviewed. Record of the patients attended at several medical camps organized at Rudraprayag, Agastyamuni, Vijaynagar, Silli, Chandrapuri, Banswara-Bhiri, Temoriaunder Rudraprayag District, and Karnprayag, Garhwal, Uttarakhand have been considered in this study. Record of the acute incidence of the problems identified and diagnosed by the registered medical practitioners, psychiatrists, psychologists, trained nurses and laboratory technician were reviewed from several registers. Gathered information from the period 23.06.2013 to 18.08.2013 was included. Final diagnosis was cross checked from the prescriptions. Among 3398 disaster affected people, diagnosed patient who got the treatment facilities till recovery were considered. Medical records of 2311 patients from 67 temporary relief camps were analyzed retrospectively. Patient demographic data, complaints, diagnoses, prognoses, injury types, dispositions, investigations, sustainable environment and means of transportation were all reviewed. Data were analyzed by using frequency distribution and measure of central tendency.

\section{RESULT}

Among the patients $41.8 \%$ were middle-aged (18-50 years), $35 \%$ were below 18 years, and $23.2 \%$ of them were 
above 50 years of age. $54.48 \%$ of the patients were male. $26.76 \%$ of them suffering from RTI, $25.33 \%$ from GI problems, $10.84 \%$ had dental problems, $10.41 \%$ skin problems, $7.41 \%$ of the victims had orthopedic problems, $5.75 \%$ ENT issues, $5.48 \%$ eye infections, $4.68 \%$ CVS problems. Again this is to be noted that $3.34 \%$ of them were suffering from UTI.

Data also depicted that $39.88 \%$ of the people was suffering from acute stress disorder. Mean $\%$ of the female suffering from stress were high than male $(29.34>27.67)$. Verbalization was better in females and elderly males. School going children suffered from anxiety and physical problems. Female students and younger age students reported more trauma experiences.

Identified risk factors were unavailability of safe drinking water, food, gathering of the victims in a small or uncovered space, severe financial losses and loss of the near and dear one respectively.

Eleven percentage (11\%) of Health care providers suffered from RTI/GI problems or occasional fever. 7\% suffered from stress, being emotional, sometimes pushing beyond physical capacity, to the level of neglect of self-care including food, occasionally ignoring group decision out of immediate impulse for some field intervention, even exposing self to danger disregarding feasibility and need assessment. Workout, group activities, sharing of experiences with the peers was done to overcome the situation under the guidance of the psychologist and team leaders. Learning from the experiences and struggles of the pioneers played a vital role to maintain mental hygiene of the care givers.

Glimpses from the Flood Relief Medical Relief Camps of Medical Service Centre, Uttarakhand Flood 2013:

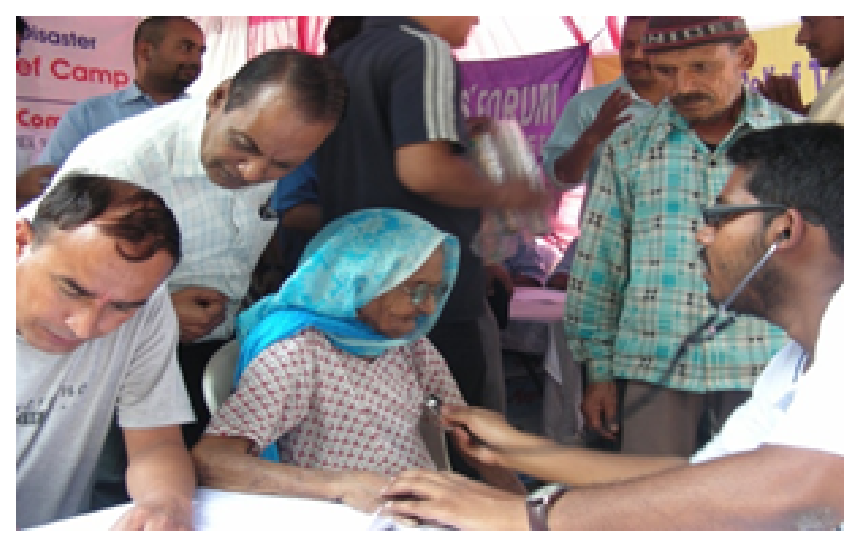

Figure 1: Base Camp Rudraprayag 29 Jun 2013

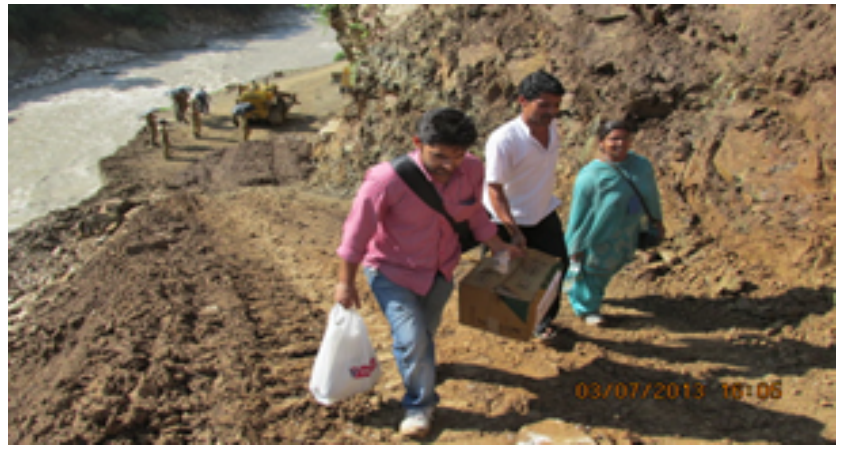

Figure 2: Medical relief Team crossing landslides to Agastyamuni 3 July 2013
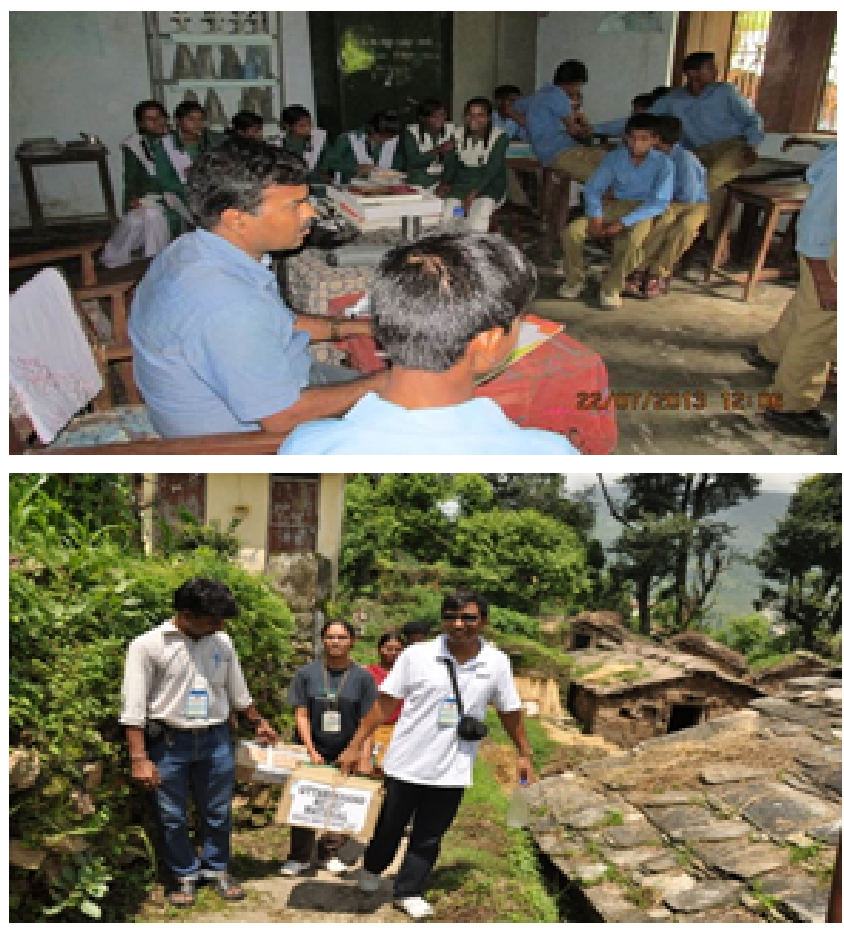

Figure 3: Reaching out to interior villages from Advance Base Camp Bhiri 10 July 2013

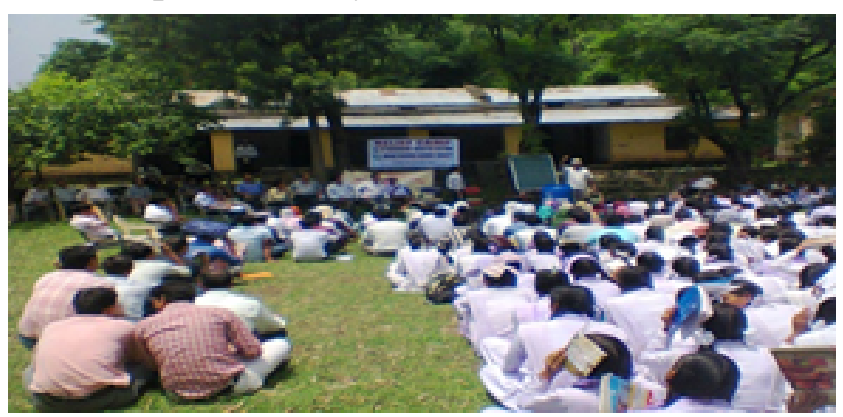

Figure 4: Water treatment training \& Health Education in GIC Ratura, 17 July 2013 


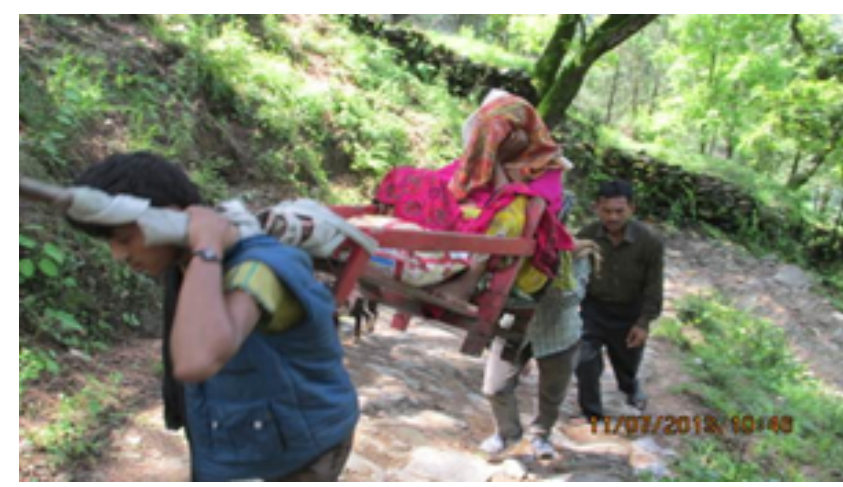

Figure 5: Carrying a patient up the slopes Chandrapuri, 11 July 2013

\section{DISCUSSION}

People suffering from severe illness were transferred to the tertiary care hospital.

Middle aged people and the children below 18 years of age were able to attend the camp. The most commonly identified problem was respiratory infections.

The victims received health care and treatment for a period of one year. People suffering from:

- Waterborne diseases, GI infections, jaundice, worm infestations on the rise; inadequate supply/availability of potable drinking water, including chlorine tablets \& bleaching powder for sanitation.

A programme for awareness-cum-training for making of filters for potable waterand its role in control of waterborne diseases, in collaboration with Breakthrough Science Society was launched and implemented.

- Skin infections (including scabies)

- Psychological trauma: grief reaction, acute stress, particularly in families having 'missing' members leading to acute disruption of life is being overlooked. Hence identification of local missing persons needs to be given equal importance to that of travellers.

Psychological First Aid training of school teachers, group activity \& group therapy created confidence.

- In the background of massive disruption of lives and livelihood of the people of the affected areas, they need to be provided with an immediate short term interim monetary relief family-wise to enable them to meet daily needs with dignity.

- Disintegration of the findings and observations to the government was appreciated.

- Recorded report of the identified problems of the care giver can be analyzed to prepare a preventive measure for them.

\section{RECOMMENDATION}

- Retrospective research work using record analysis can be done in different types of disaster

- Comparative study can be done

- Management of medical and psychological problems can be compared

- Both theory and practical exposure of the student of health care sector can be implemented

- Pre-disaster preparedness and first-aid training of the school students may be considered in the curriculum

- Effect of training on psychological first aid can be measured in pre-and post -disaster training

- Unification of electronic data entry system can be more useful.

\section{CONCLUSION}

A devastating flood occurring in a remote, mountainous region presented a variety of challenges for external medical aid. Characteristic factors such as local environment, availability of food, shelter, safe drinking water transport facilities, financial and lifestyle may contribute to physical illnesses and psychological health. Availability of the health care facilities, arrangement of temporary hospital with near to required facilities can save thousands of life in emergency. Training of Psychological First Aid to the local inhabitants proved of immense help. An effective measure with multidisciplinary approach should be developed to deal with destructive natural disasters occurring in special geographical environments. Psychological first aid to the disaster victim and care providers is the key to enhance recovery.

\section{Conflict of Interest}

The authors declare that they have no conflict of interest.

\section{ACKNOWLEDGEMENT}

1. Convey my gratitude to the victims of deadly flood and several survey teams and relief teams from the different states of India namely; Gujarat, UK, Delhi, Punjab, Maharastra, and West Bengal. 
2. Heartfelt thanks goes to the members of relief team from West Bengal namely; Dr. Ansuman Mitra, Dr. Sams Musafir, Dr. Swapan Biswas, Dr. Shubha Bhattacharya, Mr. PrasantaKumar Roy (ClinicalPsychologist), Mr. Indrajeet Banerjee, Dr. Bhabani Sarkar Das, Dr. Harekrishna Maity and Sr. Preeti Taran, and others directly or indirectly helps in gathering information and documentation.

\section{REFERENCE}

Benson C. (2016) ADB Sustainable Development Working Paper Series, Promoting Sustainable Development through Disaster Risk Management 2016(40); pp: 1-20.

Davis, R.J., Sacoby, W., Martin, A.B., Glover, S. \& Syendsen, E.R. (2010) The Impact of Disasters on Populations With Health and Health Care Disparities: Disaster Med Public Health Preparedness. 4(1) pp:30-38.
Makwana N. (2019) Disaster and its impact on mental health: a narrative review. Journal of Family Medicine and Prim Care, 2019(8) pp:3090-3095

Seto, M., Nemoto, H., Kabayashi, N., Kikuchi, S., Honda N, Kim Y., Kelman, I. \& Tomita, H. (2019) Post Disaster mental health and psychosocial support in the area affected by the Great East Japan Earth quake: a qualitative study. BMC Psychiatry, 19(1); pp: 261.

Tsubokura, M., Takita, M., Matsumura T., Hara, K., Tanimoto, T., Kobayashi, K., Hamaki, T., Oiso, G., Kami, M., Okawada T. \& Tachiya, H. (2013) Changes in metabolic profiles after the Great East Japan Earthquake: a retrospective observational study. BMC Public Health; 267(13).

Yzermans, J.C., Donker, G.A., Kerssens, J.J. Dirkzwager, J.E.A, Soeteman, H.J.R., Veen, M.H.P (2005) Health problems of victims before and after disaster: a longitudinal study in ,general practice. International Journal of Epidemiology, 34(4) pp:820-826. 